
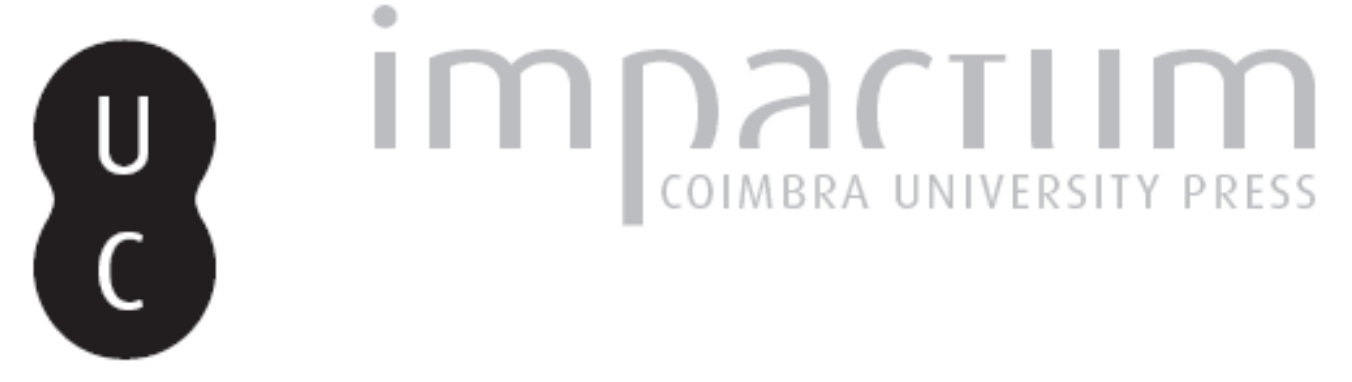

\title{
O problema da universalidade dos direitos humanos e o relativismo de sua efetivação histórica
}

\author{
Autor(es): $\quad$ Lucas, Doglas Cesar \\ Publicado por: $\quad$ Universidade Católica de Petrópolis \\ URL \\ persistente: \\ URI:http://hdl.handle.net/10316.2/33878 \\ DOI: \\ DOI:http://dx.doi.org/10.14195/2175-0947_1-2_6
}

Accessed : $\quad$ 26-Apr-2023 10:40:16

A navegação consulta e descarregamento dos títulos inseridos nas Bibliotecas Digitais UC Digitalis, UC Pombalina e UC Impactum, pressupõem a aceitação plena e sem reservas dos Termos e Condições de Uso destas Bibliotecas Digitais, disponíveis em https://digitalis.uc.pt/pt-pt/termos.

Conforme exposto nos referidos Termos e Condições de Uso, o descarregamento de títulos de acesso restrito requer uma licença válida de autorização devendo o utilizador aceder ao(s) documento(s) a partir de um endereço de IP da instituição detentora da supramencionada licença.

Ao utilizador é apenas permitido o descarregamento para uso pessoal, pelo que o emprego do(s) título(s) descarregado(s) para outro fim, designadamente comercial, carece de autorização do respetivo autor ou editor da obra.

Na medida em que todas as obras da UC Digitalis se encontram protegidas pelo Código do Direito de Autor e Direitos Conexos e demais legislação aplicável, toda a cópia, parcial ou total, deste documento, nos casos em que é legalmente admitida, deverá conter ou fazer-se acompanhar por este aviso.

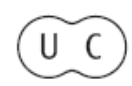



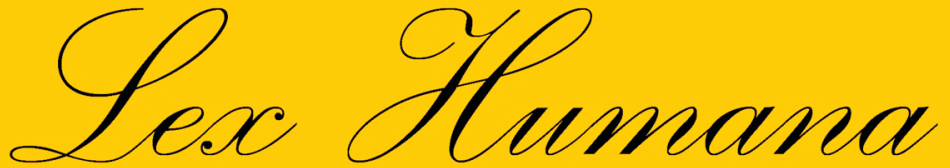

Revista do Programa de Pós-Graduação em Direito da UCP

ISSN(e) 2175-0947

Universidade Católica de Petrópolis Rua Benjamin Constant, 213 - Petrópolis - Centro CEP 25610-130

Tel: (24) 2244-4000 E-mail: lexhumana@ucp.br 


\section{O Problema dA UnIVERSALIDAdE DOS Direitos Humanos E O Relativismo DE SUA EFETIVAÇÃO HistóRICA}

Doglas Cesar Lucas ${ }^{1}$

Resumo: O presente texto defende que a universalidade dos direitos humanos não depende de leituras históricas particularistas e de movimentos comunitaristas que reclamam proteção para as suas diferenças, mas que tem sua base de sustentação na moralidade comum que é inerente ao homem como tal. Destaca, também, que a universalidade dos direitos humanos não se contrapõe ao direito à diferença, podendo, inclusive, ser a condição de possibilidade para que as diferentes manifestações humanas possam se expressar e conviver em igualdade e sem aviltamentos, impedindo que a universalidade seja confundida com homogeneização e a diferença com desigualdade.

Palavras-chave: Direitos humanos; universalidade; diferença; comunitarismo

Abstract: This paper argues that the universality of human rights does not depends on historical particular readings nor on communitarian movements that claim the protection of their differences, but that its support is found in the common morality inherent in mankind. The article also emphasizes that the universality of human rights is not opposed to the right to be different, being precisely the condition that makes possible the different human manifestations be expressed as well as people live together equally and decently, avoiding therefore that universality could be interpreted as homogeneity such as difference as inequality.

Keywords: Human rights; universality; difference; communitarianism.

1 Doutor em Direito pela UNISINOS e Mestre em Direito pela UFSC. Professor do Curso de Graduação em Direito e do Mestrado em Desenvolvimento da Universidade Regional do Noroeste do Estado do Rio Grande do Sul (UNIJUí). Professor do curso de graduação em Direito no Instituto Cenecista de Ensino Superior de Santo Ângelo (IESA). 


\section{Considerações iniciais}

O fato de os direitos humanos terem sido declarados, no segundo pósguerra, como patrimônio comum da humanidade, como um acordo universal em torno de temas imperiosos a todos os povos, não diminuiu as suspeitas e as críticas sobre a possibilidade de fundamentá-los racionalmente, sem ter que recorrer a elementos historicistas/comunitaristas. Os traços de sociabilidade contemporâneos recolocam o tema com mais força e importância, pois, afinal, as respostas para os problemas de nosso tempo exigem níveis de convergência suficientemente potentes para produzir amplos diálogos no campo político, econômico e cultural. A elaboração de um projeto global de responsabilidades comuns passa a se constituir, no momento, mais numa necessidade do que numa fatalidade do devir histórico.

Tendo presente os grandes dilemas que povoam a realidade histórica dos direitos humanos, como também a necessidade de se traduzir uma linguagem de aproximações entre as diferenças em conflito na sociedade global, o presente texto destaca que a universalidade atribuída aos direitos humanos, tão questionada pelos comunitaristas, historicistas e pós-modernos de uma maneiram geral, não nega as diferenças que constituem as diversas possibilidades de manifestação concreta/histórica da existência humana e mesmo das identidades particulares ou comunitárias. Ao contrário, reconhece que existem elementos valorativos comuns que podem ser compartilhados por todos os homens, individuais ou coletivamente, a ponto de as distintas ações e conceitos que povoam a vida histórica poderem configurar a diferença como um valor, acontecimento e característica de individualização universalizável.

Para atingir esse propósito, o trabalho foi dividido em três partes. A primeira delas é tributada à questão do problema da fundamentação universal dos direitos humanos e do relativismo de sua efetivação histórica. Nesse momento é explicitado que a universalidade dos direitos humanos não depende de leituras históricas particularistas e de movimentos comunitaristas que reclamam proteção para as suas diferenças, mas tem sua base de sustentação na moralidade comum - que é inerente ao homem como tal. Destaca-se, também, nessa fase inicial, que a universalidade dos direitos humanos não se contrapõe à diferença, podendo, inclusive, ser a condição de possibilidade para que as diferentes manifestações humanas possam se expressar e conviver em igualdade e sem aviltamentos.

O segundo item é dedicado à crítica a universalidade dos direitos 
humanos, especialmente dirigidas pelas teses comunitaristas e historicistas. No último momento o trabalho alerta para o fato de que as tradições não representam, em si mesmas, boas razões para se considerar como adequada e moralmente aceita uma prática cultural. $\mathrm{O}$ fato de um país ou determinada cultura adotar, ao longo de sua trajetória histórica, um conjunto de procedimentos que agridem a integridade física e moral de seus integrantes, por exemplo, não significa, do ponto de vista dos direitos humanos, que tais procedimentos sejam legítimos, senão que reforçam ainda mais a importância de uma fundamentação dos direitos humanos para além de ditas práticas.

\section{Algumas notas sobre o problema da fundamentação dos direitos humanos}

Há uma questão com a qual geralmente os juristas não se ocupam de modo mais rigoroso quando enfrentam o problema da fundamentação dos direitos humanos ${ }^{2}$ ou a questão de sua pretensa historicidade, e que diz respeito à capacidade $\mathrm{e}$ ao alcance do entendimento humano de responder à pergunta que interroga sobre o que os seres humanos consideram ser bom para eles e que lhes sugere uma orientação ao justo. Apesar desse questionamento (aqui apenas referido) dominar o debate filosófico desde Aristóteles, as análises jurídicas dominantes permanecem reféns de uma postura teórica que impede de se aprofundar e mesmo de se enfrentar esta premissa epistemológica relacionada com a possibilidade de o entendimento humano chegar àquilo que, em linguagem proposicional, poderia se chamar de ações humanas consideradas mutuamente necessárias e definidas como boas escolhas que permitem orientar e avaliar sobre o justo e, por isso, podem ser tomadas como o núcleo substantivo para a definição dos direitos humanos.

Para isso, é necessário perceber que o entendimento humano, segundo Ernest Tugendhat, ${ }^{3}$ é essencialmente um entendimento compartilhado, mas não simplesmente igual, que irrompe da possibilidade de dialogarmos uns com os outros e de perguntarmos sobre o "nós" na condição de "nós" como seres humanos e não reduzidamente, como um repositório autobiográfico ou cultural. Mas esse diálogo não se opera no vazio e tampouco sem

2 Um estudo sistematizado sobre a fundamentação dos direitos humanos é apresentado nas obras de RAMÍREZ, Salvador Vergés. Derechos humanos: fundamentación. Madrid: Tecnos, 1997 e de NINO, Carlos Santiago. Ética y derechos humanos. Un ensayo de fundamentación. 2. ed. Buenos Aires: Editorial Astrea, 1989.

3 TUGENDHAT, Ernest. Antropologia como filosofia primeira. In: OLIVEIRA, Nythamar de; SOUZA, Draiton Gonzaga de (Orgs.). Hermenêutica e filosofia primeira. Ijuí: Unijuí, 2006. 
interlocutores. A necessidade humana de deliberar se torna inevitável quando o pensamento humano permite à própria pessoa que pensa duvidar sobre o que está pensando, de modo que, quando deliberamos, nos perguntamos sobre as razões (boas ou verdadeiras) contra ou a favor ao que estamos dizendo ou pensando. Assim, as ações não são conduzidas apenas pela vontade intuitiva dos desejos, mas, sobretudo em razão daquilo que é bom ou verdadeiro, ou seja, pelo resultado da deliberação. A racionalidade humana não é desconectada, desligada, como diria Tugendhat, mas consiste em simplesmente poder perguntar por razões, as quais, na qualidade de humanas, ensejam perguntar sobre como devemos viver como seres humanos e não justificar modos de vida pelo fato de nos encontrarmos vinculados a uma determinada tradição, "pois o mero fato de que nos encontramos dentro de uma certa tradição não é suficiente para a justificação de como é bom viver". ${ }^{4}$

De modo geral, é até possível entender que determinadas culturas busquem suas razões, no que tange a como viver, nas autoridades do passado e até em compreensões sobrenaturais. Mas o fato de a vida humana ser impossível fora das tradições não conduz à conseqüência inevitável de que uma concepção justificada pela tradição seja uma razão suficiente para aceitá-la. Percebe-se, nesse viés, uma tendência de se supervalorizar o componente histórico enquanto conexão contínua e diacrônica da tradição, como razão e justificativa para que determinados valores sejam aceitos por uma certa cultura, praticamente de modo incondicional. Ora, é evidente que o homem vive inserido numa situação histórica; não há como fugir dessa contingência. No entanto, as normas que são produzidas no contexto dessa dada situação histórica não podem ser justificadas tão-somente a partir da história como tal, uma vez que não tem sentido "justificar que uma coisa é boa com referência à situação histórica, nem a seu passado, à tradição, e também não faz sentido justificar que uma coisa é boa referindo-se ao presente; isso significaria adequar-se a uma moda". 5 De fato, o que consideramos bom hoje ou considerávamos bom no passado não passam de fatos e quase nada contribuem a respeito da pergunta se algo é bom no sentido moral.

Nesse cenário, o elemento histórico, se compreendido como continuidade sincrônica e causal, não pode justificar valores, mesmo porque, quando se apresentam as condições temporais e causais de uma determinada concepção, se produz, também, uma relativização desta mesma concepção.

4 TUGENDHAT, Ernest. Antropologia como filosofia primeira, p. 88. 
No momento em que a tradição e a autoridade foram rejeitadas como justificadoras do bem, a moral, compreendida como o conjunto de exigências recíprocas, foi diminuída a uma esfera bem limitada. Se os valores nas sociedades primitivas eram todos definidos pela autoridade, pelas tradições e prescritos por meio de mandamentos, de modo que a dimensão do bem era toda absorvida pela moral, a rejeição do tradicional e do autoritário como instância de justificação de valores importou na possibilidade de racional e compartilhadamente o homem chegar ao entendimento sobre as boas razões que devem orientá-lo na condução de sua história, entendida agora não apenas como fatalidade e linearidade sincrônica, mas como uma abertura para possibilidades reais sobre as quais a humanidade deve deliberar.

O homem, ao libertar-se da continuidade histórica pura e simples - como fator absoluto de legitimidade -, encontra-se na condição de fazer avaliações (morais, jurídicas, econômicas, etc.) sem ter que aceitar a inevitabilidade e a veracidade emanada dos eventos históricos, como se os mesmos fossem representações continuadas e inquestionáveis de uma dada autoridade ou tradição. Essa possibilidade de avaliar instituições, ações e projetos inaugura uma nova perspectiva para a memória, para o presente e para o futuro, uma vez que a humanidade concreta, relevada nas sociabilidades muito particulares e inclusive divergentes, seja em um mesmo tempo ou em tempos diferentes, em sociedades iguais ou distintas, defronta-se com a necessidade de ter que justificar suas escolhas e deliberações levando em conta uma agenda de entendimentos compartilhados pelos seres humanos que são afetados por tais deliberações.

É verdade que não se pode viver fora da história, nem mesmo compreender o mundo afastado dela. Afinal, o homem é um ser histórico, está na história e não tem como desconsiderá-la sem desconsiderar-se enquanto tal. Sem esquecer a importante lição que nos apregoa a historicidade, é preciso reconhecer, porém, que não se pode aceitar a legitimidade das justificativas e dos fundamentos a respeito de valores morais quando a única razão para aceitá-los seria a sua referenciabilidade histórica ou cultural. De fato, é importante que se desconfie dos argumentos causais e lineares tomados como verdadeiros ou bons pelo simples fato de terem respaldo histórico. Caso fosse diferente, seria difícil encontrar novas razões para o futuro, tampouco seria possível avaliar, mesmo minimamente, a justiça e a injustiça que se produziu ao longo da história da humanidade.

Se é somente a história, enquanto acontecimento condicionante e condicionado da realidade, que permite se chegar a isso, a possibilidade de 
se avaliar moralmente - pois afinal estamos inseridos em um tempo histórico que produz realidade objetiva e sentido intersubjetivo -, não é ela em si mesma, entretanto, a história, o conteúdo moral que se persegue ou que se reprova. Quando se analisa um evento histórico ou uma dada cultura (sem poder fugir da própria historicidade é claro, pois não se é possível fugir de si mesmo), é evidente que determinados fatores que caracterizam um tempo, um espaço, enfim, uma sociedade, condicionarão a racionalidade que interroga e que responde sobre as escolhas e justificativas para uma vida boa em uma época histórica ou cultural. Mas isso não indica que não se possa perguntar e questionar sobre tais eventos históricos para além deles mesmos, que não se possa criticar a insuficiência da história como justificativa moral e, também, exigir mudanças sociais, culturais, políticas, etc., que sugerem a necessidade de se elaborar um outro tempo histórico. Ademais, a história não é necessariamente apenas uma seqüência linear de fatos, totalidade ou caos; é também memória, descontinuidade, manipulação, saber, poder, processo e resultado, ${ }^{6}$ sendo importante observar que há momentos de ruptura.

Nesse sentido, a modernidade representou uma descontinuidade em relação ao passado e inaugurou uma nova consciência espaço-tempo, ${ }^{7}$ movimento que foi particularmente percebido após as experiências monstruosas do século XX. A responsabilidade da humanidade, neste momento, como diria Jürgen Habermas, ${ }^{8}$ se volta inclusive, mas de modo novo, para o passado, para a sua história e suas tradições, com a intenção de não esquecer e de notadamente memorizar os seus erros e de sensibilizar-se com o sofrimento do outro. Assim se estabelece uma distância reflexiva a respeito da própria tradição e uma apropriação consciente da própria história, a qual, como se fosse um eco pedagógico do passado, passa a ser pensada com certa responsabilidade e seletividade típicas de quem não deseja cometer velhos equívocos.

No caso específico dos direitos humanos, é evidente que a definição jurídica e a institucionalização de seus postulados constituem o quadro das importantes conquistas históricas proporcionadas pelas revoluções liberais do século XVIII. Sob esse ângulo, é possível se afirmar que os direitos

6 LE GOFF, Jacques. História e memória. Tradução de Bernardo Leitão e outros. 5. ed. Campinas: Unicamp, 2003.

7 GIDDENS, Anthony. As conseqüências da modernidade. Tradução de Raul Fiker. São Paulo: Unesp, 1991. 
humanos tiveram um momento especial de reconhecimento institucional que se confunde com o próprio advento do Estado moderno e se configura como elemento material de sua formação, como última instância de legitimação do Estado de Direito. Mas essa constatação histórica não reduz a questão da fundamentação dos direitos humanos à conformação do Estado liberal ou até mesmo à positivação de um rol de direitos entendidos como tais. Como se sabe, as teorias positivistas manifestam que um direito somente poderá ser considerado com tal se estiver reconhecido pelo ordenamento legal. Nesse cenário, qualquer fundamento externo ao sistema legal não é válido. Nesse sentido, Hans Kelsen ${ }^{9}$ defende que o direito positivo não pode condicionar a validade de suas normas a um sistema valorativo, pois, como impera na sociedade um relativismo valorativo, impedida está a possibilidade de se encontrar um fundamento de valor que seja absoluto e último para a validade do direito.

Mas a positivação dos diretos humanos não explica, por exemplo, o porquê da definição e da escolha de determinados direitos e não de outros; não explica por que diferentes sociedades ocidentais, com história política e econômica diversas, adotaram, em regra, uma mesma orientação valorativa na definição de suas cartas políticas de direitos humanos; não explica ainda o fato de sociedades não-ocidentais concordarem, ao menos em parte, com um conjunto desses direitos mesmo antes das revoluções do século XVIII. Em outras palavras, o fato histórico do reconhecimento jurídico dos direitos humanos é de uma importância inegável para a afirmação das sociedades democráticas, mas não elide e nem mesmo nega a necessidade de uma justificação para as declarações modernas de direitos humanos.

$\mathrm{O}$ fundamento dos direitos humanos não pode depender de variações espaço-temporais, tampouco de visões particulares do mundo religioso, político, cultural, etc. Uma vez que se reporta a uma ordem comum de valores que visa justificar a aceitação de um conjunto de conceitos jurídicos e de práticas políticas que visam proteger o homem independentemente de seus vínculos institucionais ou culturais, os direitos humanos não poderão condicionar seu fundamento sem que isso também comprometa sua própria universalidade. 


\section{Apontamentos sobre a crítica historicista e comunitarista a} universalidade dos direitos humanos

É de se notar, entretanto, que o problema do fundamento não tem ocupado a agenda de preocupações de todos os estudiosos que se dedicam ao tema dos direitos humanos, especialmente porque a violação material de tais direitos, que tem sido cada vez mais gritante e assumido novas formas na sociedade global, tem monopolizado o debate político e levado à desconsideração desse problema epistemológico. Para autores como Norberto Bobbio, ${ }^{10}$ a busca de um fundamento absoluto para os direitos humanos não tem sentido, pois "o fundamento absoluto é o fundamento irresistível no mundo de nossas idéias, do mesmo modo como o poder absoluto é o poder irresistível (que se pense em Hobbes) no mundo de nossas ações”. Contra a idéia de um fundamento último ou absoluto, o autor destaca, entre outros argumentos, que os direitos humanos são direitos históricos, que são direitos relativos e decorrem da própria relatividade que constitui a história de cada povo.

Nesse sentido, acrescenta Norberto Bobbio que os direitos reconhecidos nas declarações modernas são direitos inclusive diversos entre si e, em alguns casos, até mesmo incompatíveis, o que, em seu entendimento, impossibilitaria a defesa de um fundamento único dos direitos humanos e demonstra a existência de diferentes fundamentos dos direitos do homem, "de diversos fundamentos conforme o direito cujas boas razões se deseja defender". ${ }^{11}$ De fato, sintetiza o autor, "o problema fundamental em relação aos direitos do homem, hoje, não é tanto o de justificá-los, mas o de protegêlos. Trata-se de um problema não filosófico, mas político". ${ }^{12}$

10 BOBBIO, Norberto. A era dos direitos. Rio de Janeiro: Campus, 1992. Na verdade Bobbio não considera inexistente o problema da fundamentação dos direitos humanos, mas um problema que foi satisfatoriamente resolvido pela Declaração Universal dos Direitos Humanos. Sua argumentação está centrada em duas idéias principais: 1) é impossível a busca de um fundamento absoluto para os direitos humanos e; 2) os direitos humanos não são direitos naturais, mas conquistas históricas. Para ele, não se trata de encontrar um fundamento, mas os vários fundamentos possíveis. Uma discussão sobre as teses de Bobbio e de Beuchot, sobre a proteção e a fundamentação dos direitos humanos pode ser encontrada em HERNÁNDEZ, Angel. ¿Fundamentación o protección de los derechos humanos? Las tesis de Bobbio e de Beuchot. In: Isonomia. n. 06, abril de 1997.

BOBBIO, Norberto. A era dos direitos. Rio de Janeiro: Campus, 1992, p. 20.

12

BOBBIO, Norberto. A era dos direitos, p. 24. Bobbio defende a existência de múltiplos fundamentos para os direitos humanos. Segundo ele, mesmo a busca desses fundamentos possíveis "não terá nenhuma importância histórica se não for acompanhada pelo estudo das condições, dos meios e das situações nas quais este ou aquele direito pode ser realizado. Este estudo é tarefa das ciências históricas e sociais. O problema filosófico dos direitos do homem não pode ser dissociado do estudo dos problemas 
Além da postura relativista de cunho histórico, tal como a proposta por Norberto Bobbio, outras tendências subjetivistas também não acreditam na possibilidade de se fundamentar racionalmente juízos de valor, uma vez que, por não pertencerem ao mundo do ser, impossível sua demonstração pela experiência e, conseqüentemente, inviável a comprovação da verdade ou da falsidade de seus postulados. ${ }^{13}$

Adolfo Sánchez Vázquez refere que, para o intuicionismo e o emotivismo ético, por exemplo, os “juízos morais não podem ser explicados porque são apenas a expressão de uma atitude emocional ou da tendência subjetiva a suscitar um efeito emotivo nos outros, razão pela qual só se justificam emocionalmente, isto é, de uma maneira irracional". ${ }^{14}$ Uma vez que os juízos morais cumprem, para essas tendências éticas, uma função de aprendizagem, mas apenas de cunho intuitivo, o conhecimento que tais juízos geram não serve para apresentar razões a favor ou contra um comportamento ou situação, de modo que também não se pode justificá-los racionalmente.

Da mesma forma, não são desconhecidas as objeções, diretas ou indiretas, mas sobretudo distintas entre si, contra a possibilidade de um fundamento universal para os direitos humanos, suscitadas pelas leituras denominadas pós-modernas, pelo enfoque comunitarista do multiculturalismo, pelo pragmatismo de Richard Rorty, dentre outras abordagens. Cabe registrar que tais críticas defendem, por argumentos diferentes, o particularismo e a diferença como virtudes humanas que devem ser contrapostas à idéia de universalidade, tida como uma forma de barbárie para com o homem e como negação das diferenças que permitem o florescimento das identidades. $\mathrm{O}$ particularismo, nesse caso, é apresentado contra o universalismo abstrato e racional da modernidade, uma vez que a racionalidade e a dignidade, segundo posição de Jean-François Lyotard, ${ }^{15}$ manifestam-se justamente no

históricos, sociais, econômicos, psicológicos, inerentes à sua realização: o problema dos fins não pode ser dissociado dos problemas dos meios. Isso significa que o filósofo já não está sozinho. O filósofo que se obstinar em permanecer só termina em condenar a filosofia à esterilidade. Essa crise de fundamentos é também um aspecto da crise da filosofia", p. 24.

13 PÉREZ-LUÑO, Antonio-Enrique. Derechos humanos, Estado de derecho y constitución. 6. ed. Madrid: Tecnos, 1999. Pérez Luño denomina essas teses relativistas de não-cognoscitivas, entre as quais coloca o emotivismo axiológico. O capítulo 3 da referida obra é dedicado ao problema da fundamentação dos direitos humanos.

14 VÁZQUEZ, Adolfo Sánchez. Ética. Tradução de João Dell'Anna. 21. ed. Rio de Janeiro: Civilização Brasileira, 2001, p. 248. 
empenho que o sujeito emprega para diferenciar-se de seu grupo.

A desvalorização do universal também está presente em Richard Rorty ${ }^{16}$ Segundo este pensador, não é possível uma justificação racional para a igualdade. A racionalidade com a qual os particularistas concebem a igualdade não é menor do que a existente em qualquer outra concepção de igualdade. Para ele, a justiça é uma questão de lealdade para com "os nossos", para os que são mais próximos de nós, pois a identidade moral é determinada pelo grupo ou grupos particulares com os quais o indivíduo se identifica. Deste modo, não dá para ser desleal com o grupo mais próximo sem negar-se a si mesmo, até porque nossa lealdade com os grupos mais amplos tende a ser mais fraca e ou até mesmo desaparecer na presença de grandes dificuldades.

O conflito moral entre lealdade e justiça, notado como um conflito entre os deveres de lealdade que temos com os mais próximos e os que temos com os mais distantes, necessitaria ser repensado como um conflito entre lealdades com os grupos menores e os grupos maiores. Nesse cenário, "a idéia de uma obrigação moral universal de respeito à dignidade humana é substituída pela idéia de lealdade para com um grupo mais amplo - a espécie humana". ${ }^{17}$ Um liberal deverá, então, segundo Rorty, ampliar a abrangência dos "nossos" a um mesmo grupo de lealdades, o que deverá ser feito sem recorrer à igualdade universal, mas valendo-se de uma estratégia de produção compartilhada de sentimentos por meio da educação, da literatura e dos meios de comunicação, que seja capaz de mostrar como são e o que fazem os outros, de expor que existem coisas compartilhadas entre os diversos grupos particulares e que se vive e se experimenta a dor de modo muito semelhante nos diferentes lugares.

$\mathrm{O}$ verdadeiro vínculo humano de pertença, dirão os comunitaristas mais radicais, se dá pela identidade formada dialogicamente em contato com os outros dentro de uma mesma cultura, considerada, então, como o verdadeiro fundamento dos direitos, dado que é a comunidade o marco constitutivo que torna possível a individualidade e a consciência individual. ${ }^{18}$ Cada cultura

16 RORTY, Richard. Contingencia, ironia y solidariedad. Barcelona: Paidós, 1991.

17 RORTY, Richard. Pragmatismo e política. Tradução de Paulo Ghiraldelli Jr. São Paulo: Martins, 2005. "Os dilemas morais não são, nessa perspectiva, o resultado de um conflito entre razão e sentimento, mas entre eus alternativos, autodescrições alternativas, modos alternativos de dar sentidos à vida individual. (...) Não podemos resolver o conflito de lealdades afastando-nos delas em direção a algo categoricamente distinto da lealdade - a obrigação moral universal de agir justamente", p. 106-108.

VELARDE, Caridad. Universalismo de derechos humanos. Madrid: Civitas, 2003; 
tem uma validade em si mesma; apresenta um conjunto de significados que não são transladáveis para outras culturas. Ao negar esse fato, o liberalismo, segundo Charles Taylor, ${ }^{19}$ converte a política de igual dignidade em política de discriminação, pois desconhece as diferenças culturais, reduzindo-as ao domínio de uma cultura dominante. Ao desconhecer as diferenças, o liberalismo também abre caminho para particularismos mascarados de universalismos. Assim, pode-se dizer, de modo geral, que o comunitarismo sustenta a prioridade da comunidade em relação aos interesses e prioridades dos indivíduos, defende os bens da comunidade contra uma justiça universal e reclama a proteção estatal da cultura como uma forma de vida e concepção de bem, mesmo que isso limite a autonomia pessoal e o consenso, ambos substituídos por uma legitimidade proporcionada pela tradição de uma cultura. $^{20}$

De maneira mais incisiva, Alasdair MacIntyre afirma que a moralidade original encontra-se justificada apenas na forma particular de vida social que desempenha cada indivíduo, pois as regras de moralidade somente fazem sentido em razão da específica maneira de como o homem vive sua própria história; os dados de uma vida, as particularidades morais engendradas pela família, bairro, cidade, tribo, país, etc., produzem o ponto de partida para a descoberta da identidade moral. Portanto, sentencia MacIntyre, a tentativa de fugir dessas particularidades e refugiar-se nas "máximas totalmente universais que pertencem ao homem como tal, seja em sua forma kantiana do século XVIII ou na apresentação de alguma filosofia moral analítica moderna, é uma ilusão, e uma ilusão de conseqüências dolorosas". ${ }^{21}$ MacIntyre é mais contundente ainda: uma vez que a incomensurabilidade moral é fruto de um contexto histórico particular e não de uma moralidade

RAMÍREZ, Salvador Vergés. Derechos humanos: fundamentación. Madrid: Tecnos, 1997.

19

TAYLOR, Charles. A política de reconhecimento. In: TAYLOR, Charles; et al. Multiculturalismo - examinando a política de reconhecimento. Lisboa: Piaget, 1998.

20

SANDEL, Michael. El liberalismo y los limites de la justicia. Barcelona: Gedisa, 2000. Enfim, como destaca Ermanno Vitale, apesar de não ser fácil uma definição para o comunitarismo, a ponto de muitas vezes as divergências travadas com o liberalismo serem consideradas menos de oposição do que de dicotomia, pode-se dizer que suas críticas fundamentais endereçadas à modernidade são o excesso de individualismo, o domínio da razão instrumental e a preocupação, especialmente presente em Taylor, de que tudo isso possa conduzir o mundo a uma espécie de "despotismo indulgente". VITALE, Ermanno. Liberalismo e multiculturalismo. Una sfida per il pensiero democratico. Roma-Bari: Laterza, 2000.

21 MaCINTYRE, Alasdair. Depois da virtude. Um ensaio em teoria moral. Tradução de Jussara Simões. Bauru, SP: EDUSC, 2001, p. 371. 
universal, acreditar nos direitos humanos como direitos da pessoa enquanto tal, como diziam os filósofos do século XVIII, é o "mesmo que acreditar em bruxas e unicórnios". ${ }^{22}$

\section{A Universalidade dos direitos humanos e relativismo de sua efetivação histórica: o diálogo entre compreensão histórica e fundamento ético}

Os direitos humanos não depositam sua validade no fato de serem ou não serem reconhecidos institucionalmente, mas na reciprocidade moral que obriga mutuamente todos os homens e que se torna condição de possibilidade para a existência humana individual e coletiva. Tem razão Francisco Laporta ao afirmar que "hay una imposibilidad conceptual en afirmar simultáneamente que los derechos humanos son universales y que son producto del orden jurídico positivo, porque la condición de sujeto de un sistema jurídico excluye la noción de universalidad de que estamos hablando". ${ }^{23}$ Se os direitos humanos fossem válidos e aceitos apenas quando positivos, seu alcance seria do tamanho das legislações nacionais e a sua função seria limitada ao papel de proteção de sujeitos nacionais específicos. Nessas condições, a universalidade dos direitos humanos não teria sentido algum, nem mesmo como horizonte axiológico para avaliar e pautar a ação política e jurídica legítima.

Parece ser evidente que as razões que fundamentam os direitos humanos não necessariamente promoveram, em todas as sociedades e tempos, uma mesma produção legislativa ou uma mesma prática política de reconhecimento de tais direitos. As carências obviamente não são as mesmas em todos os lugares. Porém - e esse é o ponto que nos parece central -, os fundamentos que obrigam a ação de acordo com os direitos do homem não se confundem com sua própria positividade ou materialidade histórica, isto é, nem mesmo quando já são reconhecidos juridicamente ou viabilizados tais direitos no campo prático. A universalidade, nessa senda, convive tranqüilamente com a experiência histórica, pois atualiza, sob o foco dos direitos humanos, as demandas e as condições particulares e circunstanciais presentes na realidade, as quais, por sua vez, autorizam

22 MaCINTYRE, Alasdair. Depois da virtude, p. 127.

23 LAPORTA, Francisco. Sobre el concepto del derechos humanos. In: Doxa. Cuadernos de Filosofia del Derecho. Alicante: Universidad de Alicante; Biblioteca Digital Miguel Cervantes, n. 4, 1987, p. 32-33. 
e legitimam a concreção distinta dos direitos humanos de acordo com as desigualdades apreciadas. Essa aproximação com a realidade, portanto, para além de conferir eficácia aos direitos humanos - pois permite que sejam considerados os contextos locais -, não se dá de maneira dissociada da universalidade, senão que a confirma. ${ }^{24}$ Pode-se afirmar, então, a partir das palavras de José Antonio Seone, que "si los derechos humanos aspiran a desempeñar con eficacia su función de conexión o tránsito entre los dos momentos de la dignidad, possibilitando el desarrollo de la personalidad de todos los seres humanos, han de considerar la diversidad de situaciones y de condiciones - esto es, los distintos niveles de liberdad e igualdad - presente en la realidad». ${ }^{25}$

Desse modo, não há nenhum problema em reconhecer os direitos humanos como categoria histórica no sentido de que florescem e de que são institucionalizados e efetivados, no sentido jurídico estrito, em um determinado tempo histórico. Entendê-los dessa maneira significa apenas que a história é imprescindível para se explicar a evolução das práticas e das ações que caracterizam a vida histórica dos direitos humanos, mas não para fundamentá-los, uma vez que a história em si mesma não fundamenta nada, defende Antonio Henrique Pérez-Luño. ${ }^{26}$ Nessa linha de argumentos, autores como Peces-Barba e Pérez-Luño reconhecem, a um só tempo, a universalidade dos direitos humanos e a historicidade de suas formas e de sua efetividade prática.

Peces-Barba, ${ }^{27}$ nesse viés, sustenta que os direitos fundamentais,

24 SEOANE, José Antonio. La universalidad de los derechos humanos y sus desafíos. (Los "derechos especiales" de las minorías). In: Persona y Derecho. Pamplona: Universidad de Navarra, n. 38, 1998. Para o autor, "os derechos humanos son, en este sentido, contextual o circunstancialmente universales, de manera que pueden tener en cuenta la variación de épocas, lugares y demás condiciones particulares sin prescindir por ello de su universalidad - si no se respeta esa conexión o referencia al nivel superior de los principios u objetivos básicos y universales, los derechos humanos carecerían de justificación y devendrían ineficaces e inválidos“, p. 205-206. Conferir também MARTÍNEZ-PUJALTE, Antonio-Luis. Los derechos humanos como derechos inalienables. In: BALLESTROS, Jesús (Editor). Derechos humanos. Madrid: Tecnos, 1992, p. 86-99.

25 SEOANE, José Antonio. La universalidad de los derechos humanos y sus desafíos. (Los "derechos especiales" de las minorías), p. 204.

26 PÉREZ-LUÑO, Antonio-Enrique. Derechos humanos, Estado de derecho y constitución. 6. ed. Madrid: Tecnos, 1999, p. 545. 
mesmo na qualidade de conceitos históricos, não são incompatíveis com a idéia de universalidade, uma vez que é a universalidade da moralidade básica da dignidade humana que constitui o fundamento (uma exigência moral e racional) dos direitos humanos como sendo devidos a todos os indivíduos, independentemente da posição territorial ou temporal em que se encontrem. Para ele, a universalidade racional é a da moralidade básica dos direitos, e não de cada direito como direito moral, característica que se estende tanto à idéia de universalidade no sentido temporal como territorial. Alega, ainda, que a universalidade espacial ou territorial é a meta a ser alcançada ou o ponto de chegada que precisa superar os nacionalismos e os particularismos. ${ }^{28}$ É justamente a universalidade dos valores morais que, segundo o autor, torna possível a elaboração de uma vida social de diálogos, de projetos e conceitos comuns, de escolhas conforme uma dignidade que encontra amparo na força da própria moralidade.

Pérez-Luño, ${ }^{29}$ por sua vez, apesar de já ter se guiado pela teoria discursiva e de ter fundamentado os direitos humanos na experiência e, mais particularmente, nas necessidades humanas, tem defendido, em sua posição mais recente, que os direitos humanos possuem um fundamento jusnaturalista, uma historicidade quanto à forma de manifestação e um axiologismo em relação ao conteúdo. O fato é que nenhum desses autores aceita o argumento histórico como uma boa razão suficiente para se poder tomar como corretos e como morais todos os acontecimentos de um dado período da história ou de uma cultura.

$\mathrm{O}$ fator histórico em si mesmo não nos fornece todas as justificativas para que se aceite um valor como bom em si mesmo pelo fato de ter sido pautado por uma determinada tradição. A tese historicista sobre os direitos humanos, nesse sentido, tende a sustentar a existência de um relativismo valorativo, ou seja, a existência da diversidade de valores condicionados e dependentes de uma arquitetura cultural específica, que se isola em torno de suas exigências de verdade e não permite diálogos entre realidades valorativas

28 PECES-BARBA MARTÍNEZ, Gregorio. Lecciones de derechos fundamentales. Madrid: Dykinson, 2004. Em suas palavras: "La universalidad se formula desde la vocación moral única de todos los seres humanos, que deben ser considerados como fines y no como medios y que deben tener unas condiciones de vida social que permita libremente elegir sus planes de vida. ( ) Lo universal es la moralidad básica de los derechos mismos, al menos en esta consideración a priori”, p. 202.

29 PÉREZ-LUÑO, Antonio-Enrique. Derechos humanos, Estado de derecho y constitución. 6. ed. Madrid: Tecnos, 1999; PÉREZ-LUÑO, Antonio-Enrique. Los derechos fundamentales. Madrid: Tecnos, 1995. 
distintas. Nas palavras de Mbaya, “a concepção histórica é, nesse sentido, simplista, incompleta e concentra-se na questão da realização dos direitos humanos e não sobre a própria noção; só a aceita como um fenômeno que surgiu em certo grau do desenvolvimento histórico". ${ }^{30}$

Ao se adotar a tese historicista, a aceitação do relativismo é praticamente inevitável. Uma vez que cada grupo social e somente ele torna particularmente possível a legitimidade de suas crenças, valores e sua maneira de viver e de pensar, todos os modos de vida comunitária deverão, de acordo com o pensamento historicista, ser aceitos pelo simples fato de serem a forma historicamente constituída de organização adotada por determinada coletividade. É claro que a leitura que se pode fazer dos valores de uma certa comunidade é realmente um episódio socialmente condicionado e contingente, especialmente porque dependente dos conceitos historicamente construídos que possibilitam ao homem compreender as suas próprias crenças, a si mesmo e a sua relação com o mundo. Isso, contudo, não significa que a dependência cultural e social da compreensão e, portanto, da análise objetiva de um determinado valor, conduza a uma mesma e inevitável dependência capaz de avalizar todo e qualquer valor pelo único fato de pertencer a uma prática cultural particular. ${ }^{31}$

O fundamento de um determinado valor é inteligível e, ao mesmo tempo, socialmente dependente. Justamente por isso os limites à inteligibilidade dos valores são, a um só tempo, os limites da sua própria condição material de universalidade. Assim, ou não há valores compartilhados pelo homem universalmente considerado, os quais, como defendemos, são fundamentos para os direitos humanos, ou simplesmente nada se pode conhecer a seu respeito. Por isso, uma coisa é o fundamento dos direitos humanos sustentado em uma consciência moral da humanidade em torno da importância desses direitos, mas não necessariamente em uma concepção monista de moralidade; outra é a execução material e histórica de seus postulados, circunstância que pode demonstrar níveis diferentes no que tange ao cumprimento efetivo dos direitos humanos pelos diferentes países, demonstrar, em outros termos, a carência e a dependência histórica, política

30 MBAYA, Etienne-Richard. Gênese, evolução e universalidade dos direitos humanos frente à diversidade de culturas. In: Estudos Avançados/Universidade de São Paulo. Instituto de Estudos Avançados. v. 1, n. 1 (1987). São Paulo: IEA, 1987, p. 38. 
e cultural de comunidades que não conseguem garantir materialmente os direitos que, muitas vezes, já constam em seus próprios textos constitucionais. Com efeito, o fato de algumas comunidades não garantirem um direito igual para os negros, por exemplo, não transforma a segregação racial em uma prática política e social respeitosa da condição humana universalmente considerada.

Uma vez que nem todos os valores e bens que uma sociedade elege para si, na condução de seus interesses, são tidos como mutuamente devidos pelas diferentes culturas ou entre os indivíduos de uma mesma comunidade, a definição de um núcleo axiológico e de determinadas reciprocidades é a base sobre a qual se debruça o problema da fundamentação dos direitos humanos, um problema dedicado a indagar sobre razões práticas e valorativas de se acolher juridicamente e se defender ditos direitos. O fundamento, nesse caso, dá sentido aos direitos humanos, justifica a sua aceitação universalizante, estabelece os contornos de seu reconhecimento prático e baliza a formação de seu conteúdo, além de ter uma importância prática fundamental para a avaliação das comunidades, para gerar resistências e para projetar o futuro. ${ }^{32}$ A par disso, a ausência de um fundamento objetivo e último, como lembra Carlos Correas, "transfiere una alarmante debilidad a la exigencia que los 'derechos humanos' representan; en efecto, es bien sabido (...) que la debilidad de las premisas se traslada necesariamente a las conclusiones y que, por lo tanto, si otorgamos a los derechos una fundamentación contingente y subjetiva, tendremos 'derechos humanos' contingentes, es decir, no necesarios, y subjetivos, o sea, imposibles de imponer coherentemente a los otros sujetos jurídicos". ${ }^{33}$ De fato, prossegue o autor, caso se queira levar os

32 Gregório Robles apresenta quatro razões para se fundamentar os direitos humanos: “A primeira é o absurdo de defender algum valor sem saber por quê. A segunda é o fato de o referido porquê ou fundamento delimitar o conteúdo concreto, em uma ou outra direção, dos direitos humanos. A terceira é ser francamente ridículo e inaceitável que nós, teóricos, apresentemos teorias sobre direitos sem fundamentá-las. Por último, a quarta, para conduzir à prática tais direitos é necessário, pelo menos, ter as idéias claras”. ROBLES, Gregório. Os direitos fundamentais e a ética na sociedade atual. Tradução de Roberto Barbosa Alves. Barueri: Manole, 2005.

33 CORREAS, Carlos I. Massini. Los derechos humanos en el pensamiento actual. 2. ed. Buenos Aires: Ebeledo-Perrot, S/D. O autor crítica as tentativas procedimentais e contratualistas de fundamentação dos direitos humanos, alegando que tais ensaios de justificação "modo meramente 'procedimental' o 'contractual' o 'intersubjetivo' resultan insuficientes, ya que una fundamentación sólo 'plausible' o 'razonable' - pero no estrictamente 'racional' - o 'posible', tal como la que pueden otorgar esos procedimientos, los deja - en última instancia - en manos de los mismo sujetos y asegurados por una obligatoriedad radicalmente efímera y provisoria. Además, esas fundamentaciones se aceptan por sus propios autores como meramente formales, es decir, como incapaces de fundar el contenido de los 
direitos realmente a sério, é indispensável o recurso a um fundamento último e objetivo, suficientemente potente para justificá-los contundentemente e os seus conteúdos, superando o vazio das propostas de cunho formalista e subjetivista.

Nesse viés, segundo Vicente Barretto, "a razão nuclear para que se considere o problema da fundamentação dos direitos humanos no mesmo patamar de importância analítica da sua positividade, encontra-se, portanto, no fato de que a eficácia dos direitos humanos encontra-se ligada à sua fundamentação. Essa fundamentação, entretanto, não irá depender de sua positivação jurídico-institucional, mas de sua legitimação em função de suas raízes éticas". ${ }^{34}$ Assim, para o autor, é indispensável que se construa

uma matriz conceitual, que possa estabelecer uma conceituação abrangente para esse tipo de direitos. Essa metodologia justifica-se tanto por alimentar a argumentação em favor dos direitos humanos, ameaçados e violados por regimes autoritários, como também por limitar e definir quais são e quais não são os direitos humanos. O desafio da reflexão sobre os fundamentos dos direitos humanos reside, em última análise, na busca de uma fundamentação racional, portanto universal, dos direitos humanos, e que sirva, inclusive, para justificar ou legitimar os próprios princípios gerais do direito. ${ }^{35}$

\section{Por outro lado, Alfredo Culleton destaca que a fundamentação}

derechos, con lo que termina transformándose la noción de derechos humanos en un concepto vacío y una operatividad menguada o - en última instancia - inexistente”, p. 183-184.

34 BARRETTO, Vicente de Paulo. Direitos humanos e sociedades multiculturais. In: Anuário do Programa de Pós-Graduação em Direito da Unisinos - Mestrado e Doutorado, 2003, p. 461.

35

BARRETTO, Vicente de Paulo. Ética e direitos humanos: aporias preliminares. In: TORRES, Ricardo Lobo (Org.). Legitimação dos direitos humanos. Rio de Janeiro: Renovar, 2002, p. 509. Ver, ainda, CULLETON, Alfredo. O problema da universalidade dos direitos humanos. Como e por que buscar um princípio fundador para os direitos humanos? In: VIOLA, Sólon; et al. (Orgs.). Direitos humanos. Alternativas de justiça social na América Latina. São Leopoldo: Unisinos, 2002. Para Culleton, "a fundamentação dos direitos humanos tem que ser, pois, uma fundamentação racional ou discursiva e não de autoridade. Nessa perspectiva, é uma fundamentação orientada não ao esclarecimento das bases do reconhecimento histórico desses direitos, mas ao descobrimento dos princípios racionais que conduzem até a necessidade racional de sua proteção e garantia", p. 160. 
racional dos direitos humanos é importante para se evitar que a sua universalidade sirva de estratégia ideológica ou política imperialista. Esse autor menciona, no entanto, que uma fundamentação racional tem sempre uma validade absoluta particular, uma vez que somente poderá ser válida dentro de um contexto específico e um sistema de racionalidade. Com isso, prossegue Culleton, "num universo contexto plural de racionalidades se dá sempre a possibilidade de que existam várias fundamentações absolutas dos direitos humanos". ${ }^{36} \mathrm{O}$ autor não nega a universalidade dos direitos humanos, mas a sustenta na possibilidade das diferentes racionalidades estabelecerem os seus fundamentos particulares, na proporção de suas peculiaridades conceituais.

Da mesma forma que os direitos humanos não nascem em árvores, como diriam os defensores da Teoria do Custo dos Direitos, ${ }^{37}$ tais direitos também não podem significar apenas aquilo que, por produção intersubjetiva, nossas vontades definirem como tal. Se o direito é totalmente histórico em sua fundamentação ou se ele o é em razão apenas de sua positividade, perde tempo quem pretende encontrar nele uma potencialidade universal e quem deseja avaliar a situação política e jurídica de diferentes países e culturas com base no direito. Se assim forem compreendidos os direitos humanos, de modo positivista ou historicista, cada comunidade poderá fazer de sua história, na medida de sua própria situação cultural e econômica, os fundamentos de seu projeto isolado e particular de direitos humanos.

Nesse cenário, pode-se dizer, em termos mais objetivos, que todo país pobre do Terceiro Mundo está fadado, para sempre, aos desígnios de sua própria herança social, sem que a humanidade possa fazer alguma coisa; se assim insistirmos, a soberania nacional continuará produzindo as diferenciações excludentes de sempre, e as intervenções humanitárias, mesmo que previstas nas normativas internacionais, não passarão de devaneios de um kantiano saído do exílio da universalidade. Para se evitar que os direitos

36 CULLETON, Alfredo. O problema da universalidade dos direitos humanos. Como e por que buscar um princípio fundador para os direitos humanos? In: VIOLA, Sólon; et al. (Orgs.). Direitos humanos. Alternativas de justiça social na América Latina. São Leopoldo: Unisinos, 2002, p. 163.

37 Essa teoria defende que todos os direitos são positivos e possuem um custo para serem implementados, tornando sem sentido a distinção entre direitos negativos e positivos. Referida tese foi apresentada pelos autores norte-americanos Cass Sustein e Stefhe Holmes, na obra The cost of rights. Cambridge: Harvard University Press, 1999 e tratada, entre nós, por Flavio Galdino em seus textos Introdução à teoria dos custos dos direitos. Direitos que não nascem em árvores. Rio de Janeiro: Lúmen Júris, 2005 e O custo dos direitos. In: TORRES, Ricardo Lobo (Org.). Legitimação dos direitos humanos. Rio de Janeiro: Renovar, 2002, p. 139-222. 
humanos se transformem em discurso estratégico de novos impérios ou potentes mandatos para a exortação das diferenças desumanizadoras, os direitos que se fundamentam na moralidade humana, em sua dignidade, não podem ser comparados a opiniões ou a tradições que bastam na reprodução linear e sincrônica de conceitos que se valem por si mesmos em razão de sua retórica historicista..$^{38}$

Contrariando a tese historicista de Norberto Bobbio, Liborio Hierro destaca, a respeito do fundamento moral dos direitos humanos, que "fundamentar nossos juízos de valor é uma conseqüência de nossa racionalidade reflexiva e fundamentar juízos de valor de caráter moral é ademais um requisito necessário de sua pretensão de universalidade". ${ }^{39}$ Apenas uma discussão racional no campo da filosofia moral poderá estabelecer os direitos humanos que devem ser reconhecidos como humanamente recíprocos e que fazem parte do patrimônio comum da humanidade, os direitos humanos que dizem respeito à universalidade da vida humana. De fato, somente a possibilidade de se fundamentar racional e moralmente os direitos humanos como direitos do homem em razão de sua humanidade, decorrentes da igual dignidade que é característica de cada indivíduo em sua especificidade - de modo que não fiquem condicionados ao âmbito valorativo de cada cultura, tradição ou nacionalidade -, permite que se defenda a sua abrangência universal e a sua tarefa integradora das diferenças que compõem as relações globais. Trata-se, portanto, como se pode ver, da defesa de uma universalidade no sentido propositivo e com intenção político-jurídica clara: demonstrar a pertinência dos argumentos que justificam os direitos humanos e a impossibilidade de se aceitar todo e qualquer fundamento que provoque o aviltamento humano. Se não for possível encontrar bons argumentos para se legitimar uma cultura de direitos humanos, é da mesma forma improvável que se chegue a razoáveis argumentos contrários às práticas que os direitos humanos visam combater.

A sociedade contemporânea é marcada por encontros entre relativismos culturais que evidenciam, a um só tempo, a afirmação de identidades locais e o florescimento de uma cultura global que perpassa os diferentes espaços de sociabilidade. Do mesmo modo, existe uma agenda de

38 NINO, Carlos Santiago. Ética y derechos humanos. Un ensayo de fundamentación. 2. ed. Buenos Aires: Editorial Astrea, 1989. 
problemas e de desafios que somente poderão receber atenção eficiente se forem pensados e tratados de forma global. Ou alguém acredita que o problema da fome, da água, das guerras ou do meio ambiente, por exemplo, possa ser adequadamente tratado pelo paradigma nacional e legalista dos Estadosnação? Nesse quadro de desencontros e desafios, a universalidade funciona como recurso político para a definição de uma pauta capaz de levar em frente ações de direitos humanos que afetam a humanidade como um todo. Tratase, pois, de uma universalidade que se opõe à exclusão e ao estranhamento, que denuncia o fechamento das sociedades em torno de valores que distingue e isola pelo tratamento desigual. ${ }^{40}$ Assim, por serem direitos que exigem o reconhecimento de reciprocidades universais de todos os seres humanos, servem de justificação para obrigações e responsabilidades mútuas, a serem respeitadas por todos os indivíduos e Estados, independentemente de qualquer condição. Afinal, como aponta Pérez-Luño, "los derechos humanos o son universales o no son. (...) La exigencia de universalidad, en definitiva, es una condición necesaria e indispensable para el reconocimiento de unos derechos inherentes a todos los seres humanos, más allá de cualquier exclusión y más allá de cualquier discriminación". ${ }^{41}$

\section{Considerações finais}

A universalidade atribuída aos direitos humanos não nega as diferenças que constituem as diversas possibilidades de manifestação concreta/histórica da existência humana e mesmo das identidades particulares ou comunitárias. Mas, ao contrário, reconhece que existem elementos valorativos comuns que podem ser compartilhados por todos

$40 \quad$ SAAVEDRA, Modesto. La universalidad de los derechos humanos en un mundo complejo: igualdad moral y diferencias jurídicas. In: DE LUCAS, Javier; et al. El vínculo social: ciudadanía y cosmopolitismo. Valencia: Tirant lo Blanch, 2002. Claramente preocupado em encontrar uma justificativa que proteja a universalidade dos direitos humanos dos ataques relativistas de todas as ordens, Saavedra aduz que "la idea de la universalidad se opone a la exclusión y al extrañamiento. Si los derechos humanos valen universalmente, nadie puede despojar de ellos a otros sin culpa. Esta pretensión de universalidad les es propia a los derechos humanos como ninguna otra, y por ella entendemos efectivamente, que tales derechos valen para todos los seres humanos, en todas partes, y que, como derechos individuales que son, le han de ser atribuidos a toda persona, sin que hayan de ceder ante ninguna específica forma de vida, ante ninguna tradición cultural, ni ante ninguna creencia religiosa. Y le han de ser atribuidos a toda persona por igual, sin distinción alguna derivada de su pertencia a algún grupo político, étnico, territorial, religioso, sexual o ideológico", p. 242. 
os homens, individuais ou coletivamente, a ponto de as distintas ações e conceitos que povoam a vida histórica poderem configurar a diferença como um valor, acontecimento e característica de individualização universalizável (é possível se universalizar a liberdade de religião sem universalizar uma religião, mas todas em particular e no exato limite de seu alcance).

Não há como negar a diferença sem negar a humanidade. Por outro lado, não há como sustentar a diferença fora da humanidade. Ou seja, é a humanidade a condição mesma para a diferença. Os direitos humanos, na posiçãodeuniversaisnão-homogeneizadores, precisamjustamentereconhecer que existe uma moralidade que impõe uma reciprocidade de comportamentos a todos os indivíduos e instituições como condição de possibilidade para serem freadas as diferenças que conduzem à desigualdade excludente ou mesmo à homogeneização que inviabiliza o aparecimento das diferenças comuns à humanidade do homem, diferenças que devem ser garantidas por fazerem do homem o que ele é em razão também de sua individualidade, mas desde que sejam susceptíveis de uma proteção universal. Afastar a diferença, portanto, é o mesmo que negar as possibilidades do entendimento humano tratar daquilo que, por sua moralidade, pode ser universalizado.

Quando a diferença é uma marca distintiva do homem em sua humanidade, uma condição para o exercício da própria dimensão humana, não se pode confrontar diferenças com igualdades, mas aproximá-las na exata extensão de sua complementaridade. ${ }^{42}$ Poder-se-ia dizer, inclusive, que a universalidade, nesse sentido, é assegurada pela comum humanidade e dignidade do homem, tomadas não de forma abstrata, mas em razão dos marcos concretos que caracterizam as diferenças típicas do homem em sua humanidade. ${ }^{43}$ Em outras palavras, da mesma forma que não há um modelo paradigmático do ser humano sob o viés abstrato, especificamente no que tange à sua relação com o mundo e com os outros homens, parece sensato admitir que somente é possível reconhecer essas diversas formas de manifestação da existência humana quando os indivíduos compartilham algo em comum que permite entender tais diferenças como algo inerente à humanidade, a qual, no entanto, somente deverá ser protegida se não 
caracterizar o fomento de uma diferença excludente, prejudicial à específica maneira de ser do homem histórico em sua universalidade.

Por isso a universalidade dos direitos humanos não é uma proteção abstrata do homem fora da história, da cultura, de sua finitude. Ao contrário, é o reconhecimento de reciprocidades que permitem vir à tona o discurso da diferença e histórias de vida distintas. Também a diversidade cultural, em suas diferentes facetas, viabiliza-se tão-somente na possibilidade de se viver de diferentes maneiras uma mesma humanidade que está presente em todos os homens, humanidade essa que não pode se sufocada em ninguém, pois estabelece os limites do próprio relativismo e do pluralismo, aquilo que afasta e aproxima os homens entre si em razão do que lhes é comum. ${ }^{44}$ Não se trata, portanto, da defesa de uma humanidade vazia que se concentra apenas na defesa da espécie em sentido biológico, mas de humanidade que se reconhece no diálogo, no encontro do homem consigo mesmo, com o outro e com as coisas em razão de um certo espaço público de entendimentos e de enfrentamentos. Fernando Savater tem razão quando diz que "tener humanidad es sentir lo común en lo diferente; aceptar lo distinto sin ceder a la repulsión de lo extraño". ${ }^{45}$

A falta de uma boa razão que justifique os direitos humanos sem apelos à tradição e à autoridade poderá fomentar a profusão de relativismos de todas as ordens, especialmente históricos e valorativos, que importam na negação da defesa moral de tais direitos, tornando tão cara, pois, a sua afirmação universal. As necessidades práticas da sociedade contemporânea tornam particularmente importante o problema da fundamentação dos direitos humanos para a definição de conceitos, políticas e instituições que respondam de forma efetiva às violações aos direitos humanos em escala mundial, caracterizadas como verdadeiros problemas da humanidade. Essa nova fase social inaugurada pelos fenômenos globalizantes e localizantes da economia, cultura, política, guerra, fome, crises ambientais, etc., exige mais dos direitos humanos, assim como exige mais da história material recente e futura desses direitos, exigências que cobram, indispensavelmente, ações políticas e jurídicas em nível mundial, especialmente para se garantir, pelo direito válido, a conformação de um projeto mais ousado de humanismo. Pode-se dizer que a agenda mundial dos direitos humanos dependerá, por

44 KERSTING, Wolfgang. Universalismo e direitos humanos. Porto Alegre: EdiPucrs, 2003.

45 SAVATER, Fernando. La humanidad en cuestión. In: VATTIMO, Gianni (Comp.). La secularización de la filosofía. Hermenéutica y posmodernidad. Barcelona: Gedisa, 2001, p. 271. 
exemplo, de como a humanidade irá projetar suas instituições, de como ultrapassará o nacionalismo e a soberania estatal, de como estabelecerá limites à economia, enfim, dependerá essencialmente de como compreender a universalidade e a obrigatoriedade dos direitos humanos no mosaico de dificuldades que caracteriza a sociedade contemporânea.

A universalidade dos direitos humanos configura-se em uma necessidade para a ação política e jurídica mundial a ser referenciada por padrões de validade conforme o direito, que aceita a diferença, mas não qualquer diferença. ${ }^{46}$ Abandonar o universal significa consagrar a impossibilidade de comunicação entre culturas diferentes, pois a universalidade é, segundo Paul Valadier, "um a priori segundo o qual o outro não me é assim tão estranho, (...) ou eu não lhe sou assim tão estranho (estrangeiro), que nenhuma comunicação seja possível" ${ }^{47} \mathrm{O}$ desafio para a universalidade requer empenho para se escapar da sedução dos relativismos e força para fazer da universalidade não um valor entre outros, mas um valor que permite descobrir todos os outros valores, iguais ou diferentes, que constituem a aventura humana em sua humanidade.

46 DELMAS-MARTY, Mireille. O Direito é universalizável? In: CHANGEUX, Jean-Pierre (Org.). Uma mesma ética para todos? Lisboa: Piaget, 1999. Nesse sentido, é importante ter presente, como sugere Horácio Spector, que os direitos humanos carregam consigo uma pretensão de positivação, do que decorrem duas implicações: "Primeiro, os princípios morais que podem ser considerados como direitos humanos devem configurar uma estrutura sistemática capaz de ser estabelecida e aplicada socialmente. (...) Segundo, os direitos humanos condicionam a validade jurídica dos atos realizados por autoridades nacionais". Cf. SPECTOR, Horácio. La filosofía de los derechos humanos. In: Isonomía. n. 15, octubre de 2001, p. 45. 


\section{Referências Bibliográficas}

BARRETTO, Vicente de Paulo. Direitos humanos e sociedades multiculturais. In: Anuário do Programa de Pós-Graduação em Direito da Unisinos Mestrado e Doutorado, 2003.

BARRETTO, Vicente de Paulo. Ética e direitos humanos: aporias preliminares. In: TORRES, Ricardo Lobo (Org.). Legitimação dos direitos humanos. Rio de Janeiro: Renovar, 2002.

BEUCHOT, Mauricio. Interculturalidad y derechos humanos. México: Siglo XXI, 2005.

BOBBIO, Norberto. A era dos direitos. Rio de Janeiro: Campus, 1992.

CAMPOS, Germán J. Bidart. Teoría general de los derechos humanos. $1^{\mathrm{a}}$. reimpresión. Buenos Aires: Astrea, 2006.

CORREAS, Carlos I. Massini. Los derechos humanos en el pensamiento actual. 2. ed. Buenos Aires: Ebeledo-Perrot, S/D.

CULLETON, Alfredo. O problema da universalidade dos direitos humanos. Como e por que buscar um princípio fundador para os direitos humanos? In: VIOLA, Sólon; et al. (Orgs.). Direitos humanos. Alternativas de justiça social na América Latina. São Leopoldo: Unisinos, 2002.

DE LUCAS, Javier. Algunos equívocos sobre el concepto y fundamentación de los derechos humanos. In: BALLESTROS, Jesús (Editor). Derechos humanos. Madrid: Tecnos, 1992.

DE LUCAS, Javier. Una nota sobre el concepto y la fundamentación de los derechos humanos. (A propósito de la polémica sobre los derechos morales). In: Doxa. Cuadernos de Filosofia del Derecho. Alicante: Universidad de Alicante; Biblioteca Digital Miguel Cervantes, n. 10, 1991, p. 310-311.

DELMAS-MARTY, Mireille. O Direito é universalizável? In: CHANGEUX, Jean-Pierre (Org.). Uma mesma ética para todos? Lisboa: Piaget, 1999. 
GIDDENS, Anthony. As conseqüências da modernidade. Tradução de Raul Fiker. São Paulo: Unesp, 1991.

HABERMAS, Jürgen. Identidades nacionales y postnacionales. Madrid: Tecnos, 1989.

HERNÁNDEZ, Angel. ¿Fundamentación o protección de los derechos humanos? Las tesis de Bobbio e de Beuchot. In: Isonomia. n. 06, abril de 1997.

HIERRO, Liborio L. El concepto de justicia y la teoría de los derechos humanos. In: DÍAZ, Elías; COLOMER, José Luis (Orgs.). Estado, justicia, derechos. Madrid: Alianza Editorial, 2002.

KAUFMANN, Arthur. La universalidad de los derechos humanos. Un ensayo de fundamentación. In: Persona e Derecho. Pamplona: Universidad de Navarra, n. 38, 1998.

KELSEN, Hans. O que é justiça? São Paulo: Martins Fontes, 1997, p. 23.

KERSTING, Wolfgang. Universalismo e direitos humanos. Porto Alegre: EdiPucrs, 2003.

LAPORTA, Francisco. Sobre el concepto del derechos humanos. In: Doxa. Cuadernos de Filosofia del Derecho. Alicante: Universidad de Alicante; Biblioteca Digital Miguel Cervantes, n. 4, 1987.

LE GOFF, Jacques. História e memória. Tradução de Bernardo Leitão e outros. 5. ed. Campinas: Unicamp, 2003.

LYOTARD, Jean-François. La diferencia. Barcelona: Gedisa, 1996.

MaCINTYRE, Alasdair. Depois da virtude. Um ensaio em teoria moral. Tradução de Jussara Simões. Bauru, SP: EDUSC, 2001.

MARTÍNEZ-PUJALTE, Antonio-Luis. Los derechos humanos como derechos inalienables. In: BALLESTROS, Jesús (Editor). Derechos humanos. Madrid: Tecnos, 1992. 
MBAYA, Etienne-Richard. Gênese, evolução e universalidade dos direitos humanos frente à diversidade de culturas. In: Estudos Avançados/ Universidade de São Paulo. Instituto de Estudos Avançados. v. 1, n. 1 (1987). São Paulo: IEA, 1987.

NINO, Carlos Santiago. Ética y derechos humanos. Un ensayo de fundamentación. 2. ed. Buenos Aires: Editorial Astrea, 1989.

NINO, Carlos Santiago. Ética y derechos humanos. Un ensayo de fundamentación. 2. ed. Buenos Aires: Editorial Astrea, 1989.

PECES-BARBA MARTÍNEZ, Gregorio. La universalidad de los derechos humanos. In: Doxa. Cuadernos de Filosofia del Derecho. Alicante: Universidad de Alicante; Biblioteca Digital Miguel Cervantes, n. 15-16, 1994.

PECES-BARBA MARTÍNEZ, Gregorio. Lecciones de derechos fundamentales. Madrid: Dykinson, 2004.

PÉREZ LUÑO, Antonio-Enrique. La universalidad de los derechos humanos y el Estado constitucional. Bogotá: Universidad Externado de Colombia, 2002.

PÉREZ-LUÑO, Antonio-Enrique. Derechos humanos, Estado de derecho y constitución. 6. ed. Madrid: Tecnos, 1999.

PÉREZ-LUÑO, Antonio-Enrique. Los derechos fundamentales. Madrid: Tecnos, 1995.

RAMÍREZ, Salvador Vergés. Derechos humanos: fundamentación. Madrid: Tecnos, 1997.

ROBLES, Gregório. Os direitos fundamentais e a ética na sociedade atual. Tradução de Roberto Barbosa Alves. Barueri: Manole, 2005.

RORTY, Richard. Contingencia, ironia y solidariedad. Barcelona: Paidós, 1991. 
RORTY, Richard. Pragmatismo e política. Tradução de Paulo Ghiraldelli Jr. São Paulo: Martins, 2005.

RUIZ-GALVEZ, Maria Encarnación Fernández. Del universalismo abstracto a la universalidad concreta. In: Persona y Derecho. Pamplona: Universidad de Navarra, n. 41, 1999.

SAAVEDRA, Modesto. La universalidad de los derechos humanos en un mundo complejo: igualdad moral y diferencias jurídicas. In: DE LUCAS, Javier; et al. El vínculo social: ciudadanía y cosmopolitismo. Valencia: Tirant lo Blanch, 2002.

SANDEL, Michael. El liberalismo y los limites de la justicia. Barcelona: Gedisa, 2000.

SAVATER, Fernando. La humanidad en cuestión. In: VATTIMO, Gianni (Comp.). La secularización de la filosofia. Hermenéutica y posmodernidad. Barcelona: Gedisa, 2001.

SEOANE, José Antonio. La universalidad de los derechos humanos y sus desafíos. (Los "derechos especiales" de las minorías). In: Persona y Derecho. Pamplona: Universidad de Navarra, n. 38, 1998.

TAYLOR, Charles. A política de reconhecimento. In: TAYLOR, Charles; et al. Multiculturalismo - examinando a política de reconhecimento. Lisboa: Piaget, 1998.

TUGENDHAT, Ernest. Antropologia como filosofia primeira. In: OLIVEIRA, Nythamar de; SOUZA, Draiton Gonzaga de (Orgs.). Hermenêutica e filosofia primeira. Ijuí: Unijuí, 2006.

VALADIER, Paul. A anarquia dos valores. Será o relativismo fatal? Tradução de Cristina Coelho. Lisboa: Piaget, 1998.

VÁZQUEZ, Adolfo Sánchez. Ética. Tradução de João Dell'Anna. 21. ed. Rio de Janeiro: Civilização Brasileira, 2001.

VELARDE, Caridad. Universalismo de derechos humanos. Madrid: Civitas, 
2003; RAMÍREZ, Salvador Vergés. Derechos humanos: fundamentación. Madrid: Tecnos, 1997.

VITALE, Ermanno. Liberalismo e multiculturalismo. Una sfida per il pensiero democratico. Roma-Bari: Laterza, 2000. 